\title{
Commentary: Video-assisted thoracic surgery in the era of enhanced recovery after surgery—does good perioperative care trump good surgery?
}

\author{
Timothy J. P. Batchelor, BSc, MBChB, MSc, FRCS (CTh)
}

\footnotetext{
From the Department of Thoracic Surgery, University Hospitals Bristol NHS Foundation Trust, Bristol Royal Infirmary, Bristol, United Kingdom.

Disclosures: Author has received honoraria from Medtronic and Johnson \& Johnson and consultancy fees from AstraZeneca.

Received for publication Oct 2, 2019; revisions received Oct 2, 2019; accepted for publication Oct 3, 2019.

Address for reprints: Timothy J. P. Batchelor, BSc, MBChB, MSc, FRCS (CTh), Department of Thoracic Surgery,

University Hospitals Bristol NHS Foundation Trust, Bristol Royal Infirmary, Bristol BS2 8HW, United Kingdom (E-mail: tim.batchelor@uhbristol.nhs.uk).

J Thorac Cardiovasc Surg 2020;159:299-300

$0022-5223 / \$ 36.00$

Crown Copyright (C) 2019 Published by Elsevier Inc. on behalf of The American Association for Thoracic Surgery https://doi.org/10.1016/j.jtcvs.2019.10.012
}

Surgeons are often focused on performing complex operations through small incisions with the aim of improving outcomes. Enhanced recovery after surgery (ERAS) has the same aim but represents a change in focus to encompass the entire patient journey. It describes a multimodal approach to perioperative patient care where the emphasis is on the quality of recovery after surgery. ${ }^{1}$ Those elements of patient care that delay recovery, are unnecessary, or are associated with complications are addressed in a scientific, evidence-based manner. ERAS protocols work by blunting the harmful stress response to surgery and promoting a faster recovery.

A typical ERAS pathway involves nutritional support, patient education, carbohydrate loading, maintenance of euvolemia, optimal analgesia with regional anesthesia and avoidance of opiates, and early mobilization. Such pathways have become popular across a wide range of specialties, and guidelines now exist for lung surgery. ${ }^{2}$

In this issue of the Journal, Krebs and colleagues ${ }^{3}$ pose an interesting question. Is minimally invasive lung surgery really superior to thoracotomy, or does ERAS level the playing field when comparing surgical approaches with lobectomy? Video-assisted thoracic surgery (VATS) has become the standard of care in many institutions (and guidelines) for early-stage lung cancer. VATS is associated with less pain, shorter length of stay, better preservation of pulmonary function, and better quality of life. ${ }^{4}$ However, these observations are largely based on retrospective studies subject to both selection bias and publication bias. Furthermore, the perioperative care of patients undergoing VATS has often been different (eg, single chest tubes, no epidural anesthesia) and more closely aligned to an ERAS pathway than the traditional care received by patients undergoing thoracotomy.

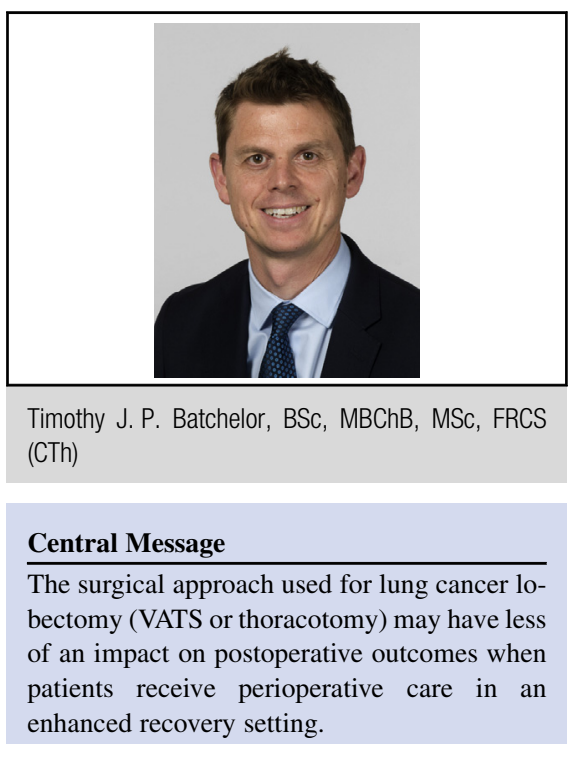

See Article page 284 .
Krebs and colleagues ${ }^{3}$ sought to compare short-term outcomes in patients on identical ERAS perioperative care pathways and undergoing lobectomy via either an open or a VATS approach. After risk adjustment, they found that the length of postoperative stay and the incidence of complications were the same for both groups. This mirrors the findings of other centers, where patients who undergo thoracotomy appear to have the most to gain from ERAS. ${ }^{5}$

So why is there so little to choose between the 2 surgical approaches in this study? One reason is that it is underpowered, with relatively small patient numbers in each group (VATS 71, open 59). The $P$ values approach significance in favor of VATS for both complications and length of stay. A larger study may have shown a statistical difference in favor of VATS. However, given the small actual differences in outcomes between the groups, it is unclear whether this would have translated into anything with clinically meaningful significance. Alternatively, it is possible that the advantages of VATS have been overplayed in the world literature, as discussed previously. Finally, as we already know that ERAS is associated with improved outcomes and it is likely that sicker patients having larger operations gain the most, this paper is actually describing the real benefits of ERAS for lung surgery. 
One randomized controlled trial has confirmed the superiority of VATS for lobectomy, albeit with only modest differences in pain and quality of life. ${ }^{6}$ The UK-based VIOLET (VIdeo Assisted Thoracoscopic Lobectomy Versus Conventional Open LobEcTomy for Lung Cancer) study, which has finished randomizing more than 500 patients to open or VATS lobectomy, has been performed in centers in which ERAS was embedded to varying degrees. ${ }^{7}$ The results are awaited. In the meantime, although it may be difficult to conclude that ERAS truly levels the playing field, it would appear that the differences between VATS and open approaches for lung cancer lobectomy are much less marked than previously thought when patients receive perioperative care in a modern multimodal enhanced recovery environment.

\section{References}

1. Ljungqvist $\mathrm{O}$, Scott M, Fearon KC. Enhanced recovery after surgery: a review. JAMA Surg. 2017;152:292-8.
2. Batchelor TJP, Rasburn NJ, Abdelnour-Berchtold E, Brunelli A, Cerfolio RJ, Gonzalez M, et al. Guidelines for enhanced recovery after lung surgery: recommendations of the enhanced recovery after surgery (ERAS $\left.{ }^{\circledR}\right)$ Society and the European Society of Thoracic Surgeons (ESTS). Eur J Cardiothorac Surg. 2019;55: 91-115.

3. Krebs ED, Mehaffey JH, Sarosiek BM, Blank RS, Lau CL, Martin LW. Is less really more? Reexamining video-assisted thoracoscopic versus open lobectomy in the setting of an enhanced recovery protocol. J Thorac Cardiovasc Surg. 2020;159:284-94.e1.

4. Yan TD, Black D, Bannon PG, McCaughan BC. Systematic review and metaanalysis of randomized and nonrandomized trials on safety and efficacy of video-assisted thoracic surgery lobectomy for early-stage non-small-cell lung cancer. J Clin Oncol. 2009;27:2553-62.

5. Van Haren RM, Mehran RJ, Mena GE, Correa AM, Antonoff MB, Baker CM, et al. Enhanced recovery decreases pulmonary and cardiac complications after thoracotomy for lung cancer. Ann Thorac Surg. 2018;106: 272-9.

6. Bendixen M, Jørgensen OD, Kronborg C, Andersen C, Licht PB. Postoperative pain and quality of life after lobectomy via video-assisted thoracoscopic surgery or anterolateral thoracotomy for early stage lung cancer: a randomised controlled trial. Lancet Oncol. 2016;17:836-44.

7. VIdeo Assisted Thoracoscopic Lobectomy Versus Conventional Open LobEcTomy for Lung Cancer (VIOLET). Available at: https://clinicaltrials.gov/ct2/ show/NCT03521375. Accessed October 2, 2019. 